\title{
Interferences of Sugarcane Glycoproteins on the Formation of Commercial Sucrose Crystals
}

\author{
Elena Sánchez-Elordi ${ }^{1}$, María Blanch $^{2}$, Carlos Vicente ${ }^{1 *}$, María-Estrella Legaz $^{1}$ \\ ${ }^{1}$ Team of Cell Interactions in Plant Symbioses. Faculty of Biology, Complutense University. 12, José Antonio \\ Novais Av., 28040 Madrid, (Spain) \\ ${ }^{2}$ Department of Characterization, Quality and Security, Institute of Food Science Technology and Nutrition \\ (ICTAN-CSIC), Madrid, Spain. \\ Email: cvicente@bio.ucm.es
}

\begin{abstract}
The aim of the present work is to study the way in which defense glycoproteins, produced by sugar cane plants, retard and modify the crystallization pattern of sucrose. The effect of defense glycoproteins against smut on the crystallization of sucrose has been studied with preference. In general, these glycoproteins delay the appearance of the first nuclei, hinder the association of individual crystals to form agglomerates or star-like nuclei, and increase the degree of surface erosion of the formed crystals. Using defense glycoproteins labeled with fluorescein isothiocyanate, it has been observed that the adhesion of these glycoproteins to the sucrose crystals is carried out mainly on the edges thereof, never on their flat faces, and never penetrates inside them, although they may move along its outer surface. The fluorescence diffuses in the zones of rupture or abrasion, indicating that the appearance of such accidents releases the proteins adhered to the free solution.
\end{abstract}

Key words: Crystallization, glycoproteins, impurities, sucrose, sugar cane.

\section{Introduction}

Within the large family of Poaceae, the genus Saccharum comprises six species characterized by different degrees of polyploidy. One of them, S. officinarum, is used in extensive cultures mainly to produce sucrose. Sugar metabolism in $S$. officinarum is directed to the synthesis and accumulation of sucrose in the parenchyma of the stems. Sugarcane produces sucrose in leaves from a part of the pool of hexose-P that are produced during photosynthesis. Sucrose-P synthase transfers a glucose moiety from UDPG to fructose-6-P to form sucrose phosphate, which is then dephosphorylated to sucrose by the corresponding phosphatase [1]. The sucrose formed will then be transported to the stem to be stored in their internodes or used, after its hydrolysis, in respiratory processes. During the ripening stage, any remaining glucose, fructose and other soluble carbon are converted back into sucrose for storage [2].

Secondarily, some soluble polysaccharides may transiently accumulate along with sucrose [3-5]. These polysaccharides can be naturally produced by the plant, such as starch [6] or to appear as a defense response against pathogens [7-8]. Anyway, they can interfere with the industrial process of crystallization of sugar, reducing the yield of its production and giving rise to obtain a product whose appearance and properties produce the rejection of the consumer. Therefore, knowing the origin of these polysaccharides and their attachment mechanisms to the sucrose crystals during the purification process is of vital importance in order to avoid irreversible economic losses.

\section{The Manufacture of Sucrose from Sugar Cane for Food Industry}

The manufacture of sugar for food industry can be summarized as follows [9]. To extract the juice, the cane stalks are crushed with rotary blades and a shredder before grinding to facilitate the extraction of the juice in the mills. Generally, between four and seven mills are used, passing the bagasse from one to another by means of conductors with clutch to avoid the deterioration of maces by hard objects. To optimize the extraction, water is used in countercurrent, obtaining up to $95 \%$ of the sugar contained in the cane stalks. This constitutes the first stage of processing raw sugar manufacturing. 
The dark-green juice drawn from the mills is acid and turbid. The process of clarification, designed to remove both soluble and insoluble impurities, generally uses calcium oxide and heat as clarifying agents. Lime slurry, around $0.5 \mathrm{~kg} \mathrm{CaO}$ per ton of cane, neutralizes the natural acidity of juice, forming insoluble calcium salts. The clarified, clear and brownish juice passes to the evaporators without further treatment. This juice contains about $85 \%$ water. Two-thirds of this water is evaporated in multi-effect vacuum evaporators. To obtain sugar for direct consumption, the juice is then subjected to the carbonation process using the combustion gas at $300{ }^{\circ} \mathrm{C}$ after the first evaporation and filtered before the next two stages of evaporation. The cooked mass can be centrifuged to obtain a crystalline product.

The massecuite (a mixture of crystals and molasses) is then transferred to the pans where the evaporation of water continues. This causes crystallization of the sugar $[10,11]$. The pans work with vacuum to effect the evaporation at low temperature and to avoid the caramelization of the sugar. At this time, seeds (small balls of purified sugar) are added to serve as a primer for the sugar crystals formation, and more syrup is added as the water evaporates. The growth of the crystals continues until the pan is filled. From the pans, a mass, denominated cooked mass, is obtained consisting on a mixture of crystals of sugar and molasses. The separation of both is done by centrifugation. From the centrifuges comes raw sugar and molasses. The molasses is returned to the pans for two additional stages of crystallization that ends in molasses.

\section{$3 \quad$ Impurities}

Usually, the juice (guarapo) owes its color to pigments of the flavonoid family and the waxes that cover the outermost side of the cane. In addition, some soluble polysaccharides may transiently accumulate, along with sucrose. For example, small amounts of arabino-galactans [5], starch-like glucopolysaccharides [3] containing some of their branches consist of 1,6-glucans [4], as well as 1,4glucans [12]. Arabinogalactan also occurred as having a frame work of (1-3)-linked B-D-galactose residues of which two out of every three carry a galactosyl or arabinosyl side chain attached at 1-6 positions [13]. L-arabinofuranosyl residues as single units and small side chain predominate at the branches. Galactosyl residues are attached in small chain linked.

However, under special stress conditions, sugar cane plants can synthesize soluble heterofructans composed of a fairly extensive domain of $\beta$-1,2-fructo-furanoside chains in which galactitol units or short segments of polygalactitol are intercalated [14]. These heterofructans have been tentatively classified into two groups according to their molecular mass: High molecular weight carbohydrates (HMMC), composed by more than 100 monosaccharide units [15], and mid-molecular mass carbohydrates (MMMC), composed from 10 to 50 monosaccharide units [16]. The stress circumstances that provoke their accumulation in detriment of that of sucrose are usually conditions of deterioration of the cut stems: collection at the post-ripening stage (aged stems), number of cuts applied on stems or low oxygen tension during transport and storage [17, 7-8]. Usually, these heterofructans appear as polysaccharide moities of several glycoproteins, called then high molecular weight glycoproteins and mid-molecular mass glycoproteins.

Fontaniella et al. [18] demonstrated that the colligative properties of the peptide moiety of both HMMG and MMMG enable the binding of these glycoproteins to crystalline surface of sucrose, using probably the lower face of the prismatic crystals to adhere to it. This hampers the formation of star-like complexes. When polysaccharide and protein moieties separate, carbohydrate is unable to impede the formation of these complex crystals [19], as well as heterofructans obtained from impaired sugar beet, that do not contain the peptide moiety. This can be interpreted as a probe that the binding of both HMMG and MMMG to sucrose crystals is due to the formation of hydrogen bonds between some amino acids of the peptide moiety and sucrose.

On the other hand, leaf scald disease of sugar cane, produced by the phytopathogenic bacterium Xanthomonas albilineans, causes yield losses of sucrose production in both field and factory (reduction of the quantity and quality of the juice extracted from the sugar cane stalks). Xanthan-like gum [20], the synthesis of which is activated by HMMG and MMMG action [21], is able to modify the crystallization sequence of sucrose, a product of primary commercial interest of this culture [22]. 


\section{Sucrose Crystallization}

Typical sugar crystals are shown in Fig. 1A-D, with the directions of the crystallographic axes identified (Fig. 1E). Shape variations mainly result in variations in the relative magnitudes of $\mathrm{A}, \mathrm{B}$ and $\mathrm{C}$, while the general appearance of the crystal (as shown in Fig. 1C and D) is retained. The type of elongation most commonly observed in cane sugar is in the $\mathrm{C}$ axis direction [23].

Sucrose crystallizes in supersaturated aqueous solutions [24]. The complete process of crystallization of sucrose consists of the formation of crystalline nuclei and their subsequent growth. The first appearance of nuclei generally occurs after the organization of hydrated sucrose molecules in swarms during a period of pre-nucleation. This first nucleation is carried out by the formation of hydrogen bridges between molecules of sucrose, for which it is necessary that the sites that could potentially form these bonds were not occupied by water of hydration. After the appearance of individual nuclei, agglomerates of two or three crystals are formed (Fig. 1A and B). During crystal growth (Fig. 2), incorporation of sucrose molecules to the crystal lattice also requires that the hydration water molecules were disassociated [25]. This step seems to constitute an energy barrier to crystal growth higher than the barriers of diffusion or viscosity.

From saturated solutions, sucrose forms crystals of monoclinic sphenoidal system [26], which aggregate in complexes agglomerates (Fig. 1C) or in star-like crystallization nuclei (Fig. 3A-C). The first nuclei do not appear before $2 \mathrm{~h}$ of solvent evaporation, according to de Armas et al. [22]. From this moment, nuclei composed by two or three crystals are produced which aggregates thereafter to form characteristic star-like structures. The increase in the number of nuclei shows to be a complex function that can be fitted to the equation $\mathrm{y}=2.78 \mathrm{x}^{2}-10,93 \mathrm{x}+9.14$ (Fig. 4), where $\mathrm{y}$ is the number of nuclei and $\mathrm{x}$, the time. The crystals and the star-like aggregates completely develop $4.5 \mathrm{~h}$ after the beginning of the experimental recrystallization process [22].

\section{Modifications of the Pattern of Sucrose Crystallization in the Presence of Impurities}

It is generally accepted that sugar cane polysaccharides have greater tendency to go preferentially into the sugar crystal and, thus, impact refined sugar quality [13]. These high molecular weight polysaccharides negatively affect sugar processing and have been implied in the inclusion of color in crystals and formation of color during storage [27]. Other polysaccharides, such as dextrans, formed in sugarcane juices [28] as a result of occasional bacterial contamination, are responsible for sucrose loss and are due to producing false polarization values as a consequence of their high positive specific rotation. The occurrence of polysaccharides in juices during sucrose purification also results in an increase of viscosity. High viscosity values decrease the sucrose crystallization rate, heat transfer in the evaporators, crystallizers and pans, and also decrease both sucrose yield and quality [29]. Saska and Oubrahim [30] reported that the crystallization rate of sucrose at high impurity concentrations proved to be satisfactory. The crystallization rate was an exponential function of impurity degree (I/W), according to the equation

$$
R=52.7 h^{-4.74(W / I)}
$$

which could be rewritten as

$$
R=C r(i)-C r(i-1) /[S(i-1)] \cdot[\theta(i)-\theta(i-1)] 6,
$$

where $\operatorname{Cr}(\mathrm{i})$ and $\operatorname{Cr}(\mathrm{i}-1)$ are crystal weight at instants $\theta(\mathrm{i})$ and $\theta(\mathrm{i}-1)$ respectively, and $\mathrm{S}$ is the surface of crystal obtained from size or mean aperture (M.A.) as: $\mathrm{S}=0.4 / \mathrm{M}$.A.

Not only the sugarcane polysaccharides that are recovered into the juices after grinding the stems and are not completely eliminated can interfere with the crystallization of sucrose. In some cases, bacterial pathogens that cause fastidious diseases secrete polysaccharides intended to occlude the xylem vessels and produce leaf desiccation [31, 32]. Such is the case of the disease called leaf scald, produced by Xanthomonas albilineans. These bacterial polysaccharides are also recovered in the juices and, unless they are completely excluded from them, may interfere with the crystallization of the sugar (Fig. 5). Sucrose crystallization from the juices of the sugar cane cv. Barbados 42231 stalks (sensible to the disease) inoculated with $X$. albilineans showed notable differences by comparison with that observed for 
juices obtained from stalks of healthy plants. The number of sucrose crystals obtained drastically decreased when juices obtained from plant inoculated with $X$. albilineans were used as a source of sucrose. In addition, very few of these crystals showed the typical agglomeration of prisms in complexes with a star shape and many of them appeared sensibly eroded (Fig. 5). The less complex nuclei were amorphous or, on the contrary, individual prisms showed a small degree of aggregation (4-5 prisms for each complex). This would indicate that xanthans, secreted by the bacteria and recovered in juices obtained from infected stalks, blocked the center of adhesion of individual crystals [33].

This in vivo assay can be simulated by adding purified bacterial xanthans from $X$. albilineans to known solutions of sucrose so that these xanthans modify the sugar crystallization behavior. Adhesion of individual crystals in star-like aggregates failed in some extent and several crystals were broken during the re-crystallization process. The rate of sucrose crystallization can be fitted to a straight line, the equation of which is $\mathrm{y}=5.03 \mathrm{x}-7.93$ (Fig. 4). However, sucrose in the control aqueous solutions, without added xanthanes, initiates crystallization forming the first prismatic nuclei whose lateral walls gradually grow and they agglomerate by contacting their small inferior faces to form the star-shaped crystals.

\section{Defence Sugar Cane Glycoproteins Interferes with Sucrose Crystallization}

Smut is fungal disease produced by the fungus Sporisorium scitamineum. One of the main defense responses of cane plants against smut is the production of defense glycoproteins between which at least six different proteins have been identified. The glycoprotein fraction is composed by a dirigent protein related to lignification, a cytoagglutinating factor that exhibits arginase activity, three cell wall hydrolytic enzymes, such as chitinase and $\beta-1,4-$ and $\beta-1,3$-glucanases, and one chemotaxis factor not yet identified [34]. Obviously, these glycoproteins are also recovered in the juices and grouped into the so-called HMMG.

HMMG sugarcane glycoproteins from inoculated and non-inoculated plants of both resistant and sensitive varieties have been purified from stalks as previously described [35]. The pool of HMMG obtained from the resistant cv. Mayarí 55-14 has been used to analyze the influence of these glycoproteins on the recrystallization pattern of sucrose from concentrated aqueous solutions. Addition of HMMG to sucrose solutions retards crystal appearance about $1 \mathrm{~h}$ beyond the time requires by the control in distilled water [22] but, from this moment, the number of nuclei linearly increases. The relationship between these values and the time of re-crystallization can be fitted, by linear regression, to a straight line (Fig. 4) the equation of which is $\mathrm{y}=12.5 \mathrm{x}-37.1$. The pattern of crystal elongation can be measured by the ratio of clinoaxis to ortoaxis (Fig. 3D). The value of this ratio from the control crystals was 1.17, very similar to that found for crystals formed in the presence of HMMG. In a similar way, the longitudinal main axis (a) of the vertical sphenoid does not seem to be increased or decreased. The ratio control to HMMG for the main axis is 1.11. However, HMMG clearly diminished the length of the secondary b and c axes (Fig. 6). As a consequence, sucrose crystals formed in the presence of HMMG are as long as those produced in aqueous solutions but finer that these later.

To verify that the modifications reported herein in the crystallization pattern were due to an interaction between HMMG and crystals of sucrose during their formation, we proceeded to recrystallize commercial sucrose in the presence of HMMGs labeled with a fluorophore. Firstly, aliquots of $3.0 \mathrm{~mL}$ of HMMG from Mayarí 55-14 (0.41 $\left.\mathrm{mg} \mathrm{mL}^{-1}\right)$ were mixed with $3.0 \mathrm{~mL} 10 \mathrm{mM}$ fluorescein isothiocyanate for $2 \mathrm{~h}$ at room temperature in the dark with vigorous shaking. After this, mixtures were dialyzed against $5 \mathrm{~L}$ of $10 \mathrm{mM}$ sodium phosphate buffer, $\mathrm{pH} 6.8$, for $24 \mathrm{~h}$ at $4^{\circ} \mathrm{C}$ to remove free fluorophore [36]. The dialyzed volume, containing labeled fluorescent macromolecules, was collected and used for binding experiments.

These experiments have been specifically designed to complete the previous results discussed in this paper. The results obtained using this technique are shown in Fig. 7. Fig. 7A-C show the evolution of new sucrose crystals formed in a solution of $20 \%(\mathrm{w} / \mathrm{v})$ sugar in distilled water, from the simplest individual crystals to the beginning of the shaped star-like groups. The presence of HMMG, at a concentration of $0.625 \mathrm{mg}-\mathrm{mL}^{-1}$ in the recrystallization water, retards the appearance of crystals and their evolution towards more complex nuclei (Fig. 7D-G) although it allows the crystals to continue to 
grow along the c axis (Fig. 2B). Several facts, however, are worth highlighting. The first of these is that fluorescein-green fluorescence was observed exclusively on the edges of the crystals and never on their flat faces. That is, the HMMG-FITC complex adheres to the edges of the crystals and never to their flat surfaces. Secondly, the residual fluorescence at the fracture zones of the crystal structure is very weak, indicated in Fig. 7E and $\mathrm{F}$ by red arrows, by comparison to that observed on the intact edges. Finally, the fluorescence lines can move inside the crystal without spreading over their flat faces, but anchored as thin lines of adhesion on the edges (yellow arrows in Fig. 7E). This means that the HMMG does not actually diffuse inside the crystal, but are restricted to its strict surface.

The cane glycoproteins bond by adhesion, involving the formation of hydrogen bonds, to the areas of the sucrose crystal whose aqueous coating exhibits the minimum value of surface tension. These areas will obviously be the edges, since the perimeter of the different faces of a crystal will always be greater than the length of one of its sides. This is because the value of the surface tension is a function of the force exerted by the adherent surface divided by the perimeter of said surface. Since the HMMG fraction contains a majority of anionic proteins [37], the adhered glycoproteins will further decrease the surface tension of the aqueous layer coating them, possibly by the formation of hydrogen bonds between the water and some hydroxyl amino acids units of the peptide moiety of the HMMG [18]. In other words, cane glycoproteins are assuming the role developed by the new sucrose crystals as dissociative agents of hydration water, a mechanism that allows the formation of agglomerates [25]. Therefore, the number of agglomerates decreases when recrystallization is carried out in the presence of contaminating glycoproteins.

On the other hand, the ease of moving these glycoproteins on the edges (Fig. 7E), without penetrating the inside of the crystal, justifies the proliferation of fracture zones in the agglomerates (Fig. 7F), less frequent in crystals formed in the absence of impurities. The perimetral adhesion of the cane glycoproteins on the edges that form the upper or lower faces of the crystal must act as a kind of sliding compression strip, able to move on the surface of the crystal until it embraces an area that has an internal dislocation line. That is, the surface adhered glycoproteins delimit a circuit of Burgers that can transform firstly the dislocation to torsion and then break if the pressure caused by the adhesion forces is sufficiently intense [38].

This merely adhesive behavior is fundamentally different from that observed for colored substances, which, from the molasses, can be associated with sucrose crystals. In this case, when the crystals are growing from a solution having coloring matter, inclusion is achieved on the faces lying on the top and the bottom of the c-axis (Fig. 1E). These substances cause the slowing down mainly of the p' faces and penetrate inside the crystal [39]. So, the colored crystal becomes elongated along the c-axis, as de Armas et al. [22] have also described it.

\section{Conclusions and Perspectives}

The glycoproteins that the sugarcane plants produce as a defense response to the smut illness are anionic peptides, able to form hydrogen bonds between their hydroxyamino acids and the water of hydration fixed on the surface of the sucrose crystals, thus preventing both their growth and agglomeration. The perimetral adhesion of these glycoproteins to the contour of the crystals can cause their constriction that end in breakage of the crystal. To avoid loss of productivity during the crystallization process, it would be highly desirable to remove these glycoproteins, either by ethanolic precipitation and subsequent centrifugation, or by molecular exclusion procedures.

Acknowledgements This work was in a part supported by a grant from the Agencia Española de Cooperación Internacional (AECI, Spain) A/018020.08

\section{References}

1. J. Wang, S. Nayak, K. Koch, and R. Ming, "Carbon partitioning in sugarcane (Saccharum species)," Frontiers in Plant Science, vol. 4, paper 201, doi: 10.3389 / fpls.2013.00201, 2013. 
2.A. Whittaker, and F.C. Botha, "Carbon partitioning during sucrose Accumulation in sugarcane internodal tissue," Plant Physiology, vol. 115, pp. 1651-1659, 1997.

3. M.T. Covacevich, and G.N. Richards, "Studies on dextrans isolated from raw sugar manufactured from deteriorated cane. Part I. Isolation, purification and structure of dextrans," International Sugar Journal, vol. 79, pp. 3-9, 1977.

4. M.T. Covacevich, and Richards, "Studies on dextrans isolated from raw sugar manufactured from deteriorated cane. Part II. Determination of structure using a bacterial dextranase," International Sugar Journal, vol. 79, pp. 33-37, 1977.

5. E.J. Roberts, M.E. Godshall, F.G. Carpenter, and M.A. Clarke, "Composition of soluble indigenous polysaccharides from sugar cane," International Sugar Journal, vol. 78, pp. 10-12, 1976.

6. F.K. Imrice, and R.H. Tilbury, "Polysaccharides in sugar cane and its products," Sugar Technology Reviews, vol. 1, pp. 291-361, 1972.

7. P. Valdes, and C.W. Rodriguez, "Formación de polisacáridos en tallos de caña de azúcar recién cortados," Ciencias de la Agricultura, vol. 12, pp. 45-52, 1982.

8. P. Valdes, and C.W. Rodriguez, "Respuestas de los tallos de la caña de azúcar a los cortes," Ciencias de la Agricultura, vol. 12, pp. 118-122, 1982.

9. K. Schlumbach, A. Pautov, L. Göckeritz, A. Bagherzadeh, and E. Flöte, "Controlled sucrose crystallization at pilot-plant scale," Sugar Industry, vol. 140, pp. 500-507, 2015.

10.R. Broadfoot, and R.J. Steindl, "Solubility-crystallisation characteristics of Queensland molasses," Proceedings of the International Society of Sugar Cane Technologists, vol. 17, pp. 2557-2581, 1980.

11.P.W. Rein, and G.S. Cox, "Syrup clarification in raw sugar mills," Proceedings of the South African Sugar Technology Association, vol. 61, pp. 22-31, 1987.

12.E.J. Roberts, M.A. Clarke, M.E. Godshall, and F.W. Parris, "A glucan from sugar cane," International Sugar Journal, vol. 87, pp. 227-231, 1985.

13.D.B.S. Chauhan, O.P. Gupta, S. Kumar, and V. Kumar, "Identification of polysaccharides from Indian sugar," Journal of Applicable Chemistry, vol. 3, pp. 720-724, 2014.

14.M.E. Legaz, L. Martín, M.M. Pedrosa, C. Vicente, R. de Armas, M. Martínez, I. Medina, and C.W. Rodríguez, "Purification and partial characterization of a fructanase which hydrolyzes natural polysaccharides from sugar cane juice," Plant Physiology, vol. 92, pp. 679-683, 1990.

15.R. de Armas, M. Martínez, C.W. Rodriguez, M.E. Legaz, J.L. Mateos, S.V. Caffaro, and C. Vicente, "The chemical nature of high molecular mass heterofructans from cane juice," International Sugar Journal, vol. 94, pp. 147-149, 1992.

16.M.E. Legaz, R. de Armas, I. Medina, S.V. Caffaro, M. Martínez, J.L. Mateos, C.W. Rodríguez, and C. Vicente, "An approach to the chemical structure of sugar cane mid-molecular weight heterofructans," Plant Physiology (Life Science Advances), vol. 11, pp. 131-140. 1992.

17.M. Martínez, M.E. Legaz, M. Paneque, R. Domech, R. de Armas, I. Medina, C.W. Rodríguez, and Vicente, "Glycosidase activities and polysaccharide accumulation in sugar cane stalks during post-collection impairment," Plant Science, vol, 72, pp. 193-198, 1990.

18.B. Fontaniella, A.M. Millanes, D. Piñón, C.W. Rodríguez, C. Vicente, and M.E. Legaz, "Effect of leaf scald on the content of sucrose and polysaccharides of two sugar cane cultivars," Food Science and Biotechnology, vol. 12, pp. 346-350, 2003.

19.C. Vicente, B. Fontaniella, and M.E. Legaz, "Fructan-like polysaccharides produced by sugar beet during deterioration," International Sugar Journal, vol. 102, pp. 250-256, 2000.

20.M. Blanch, M.E. Legaz, and Vicente, C. "Structure and biosynthesis of a xanthan-like polysaccharide produced by Xanthomonas albilineans," Functional Plant Science and Biotechnology, vol. 6, pp. 85-90, 2012.

21.M. Blanch, D. Piñon, C. Vicente, and M.E. Legaz, "Sugar cane glycoproteins are required to the production of an active UDP-glucose dehydrogenase by Xanthomonas albilineans," Annals of Microbiology, vol. 57, pp. 217-221, 2007.

22.R. de Armas, J.L. Mateos. S.V. Caffaro, M.E. Legaz, and C. Vicente, "Changes in sucrose crystal shape induced by cane juice fructans," International Sugar Journal, vol. 94, pp. 141-143, 1992.

23.G. Mantovani, I.G.Gill, and Fagioli, "Einfluss der Kristallstruktur von Nichtzuckerstoffen auf die Änderung des Habitus von Saccharose," Zucker, vol. 20, pp. 663-668, 1967. 
24.I.A. Khaddour, L.S.M. Bento, A.M.A. Ferreira, and F.A.N. Rocha, "Kinetics and thermodynamics of sucrose crystallization from pure solution at different initial supersaturations," Surface Science, vol. 604, pp. 1208-1214, 2010.

25.M. Mathlouthia, and J. Genotelleb, "Role of water in sucrose crystallization," Carbohydrate Polymers, vol. 37, pp. 335-342, 1998.

26.N. Faria, M.N. Pons, S. Feyo de Azevedo, F.A. Rocha, and H. Vivier, "Quantification of the morphology of sucrose crystals by image analysis," Powder Technology, vol. 133, pp. 54-67, 2003.

27.M.A. Godshall, M.A. Clarke, C.D. Dooley, and E.J. Roberts, "Large colorants and polysaccharide molecules in raw cane sugars," Proceedings of the Sugar Industry Technologists, vol. 46, pp. 193-211, 1987.

28.E.C. Vignes, "Notes on cane starch and its determination," Proceedings of the International Society of Sugar Cane Technologists, vol. 15, pp. 1288-1295, 1974.

29.J.P. Murray, "Filtering quality of raw sugar: influence of starch and insoluble suspended matter," Proceedings of the Annual Congress of the South African Sugar Technologists Association, vol. 46, pp. 116-132, 1972.

30.M. Saska, and Y. Oubrahim, "Crystallisation rate of sucrose at high impurity concentrations," International Sugar Journal, vol. 91, pp. 109-115, 1989.

31.M.J. Davis, A. Graves-Gillaspie, A. K. Vidaver, and R.W. Harris, "Clavibacter: a new genus containing some phytopathogenic coryneform bacteria, including Clavibacter xyli subsp. xyli sp. nov., subsp. nov. and Clavibacter xyli subsp. cynodontis subsp. nov., pathogens that cause ratoon stunting disease of sugarcane and bermudagrass stunting disease?," International Journal of Systematic Bacteriology, vol. 34, pp. 107-117, 1984.

32.A.H. Purcell, and D.L. Hopkins, "Fastidious xylem-limited bacterial plant pathogens," Annual Review of Phytopathology, vol. 34, pp. 131-151, 1996.

33.M. Blanch, C.W. Rodriguez, M.E. Legaz, and C. Vicente, "Modifications of sucrose crystallization by xanthans produced by Xanthomonas albilineans, a sugar cane pathogen," Sugar Technology, vol. 8, pp. 255-259, 2006.

34.E. Sánchez-Elordi, L. Morales de los Ríos, E.M. Díaz, A. Ávila, M.E. Legaz, and C. Vicente, "Defensive glycoproteins from sugarcane plants induce chemotaxis, cytoagglutination and death of smut teliospores," Journal of Plant Pathology, vol. 98, pp. 493-501, 2016.

35.E. Sánchez-Elordi, L. Morales de los Ríos, C. Vicente, M.E. Legaz, "Sugar cane arginase competes with the same fungal enzyme as a false quorum signal against smut teliospores," Phytochemistry Letters. Vol. 14, pp. 115-122, 2015.

36.M.C. Molina, and C. Vicente, "Correlationships between enzymatic activity of lectins, putrescine content and chloroplast damage in Xanthoria parietina phycobionts," Cell Adhesion and Communication, vol. 3, pp. 1-12, 1995.

37.M.E. Legaz, M.M. Pedrosa, R. de Armas, C.W. Rodríguez, V. de los Ríos, and C. Vicente, "Separation of soluble glycoproteins from sugar cane juice by capillary electrophoresis," Analytica Chimica Acta, vol. 372, pp. 201-208, 1998.

38.X. Wu, S.R. Kalidindi, C. Necker, and A. Salem, "Prediction of crystallographic texture evolution and anisotropic stress-strain curves during large plastic strains in high purity a-titanium using a Taylor-type crystal plasticity model," Acta Materialia, vol. 55, pp. 423-432, 2007.

39.G. Mantovani, G. Vaccari, G. Sgualdino, D. Aquilano, and M. Rubbo, "Coloring matter inclusions in sucrose crystals," Proceedings of the IX Congress of International Society of Sugar Cane Technologists, pp. 663-669, 1986. 


\section{Appendix: Figures}
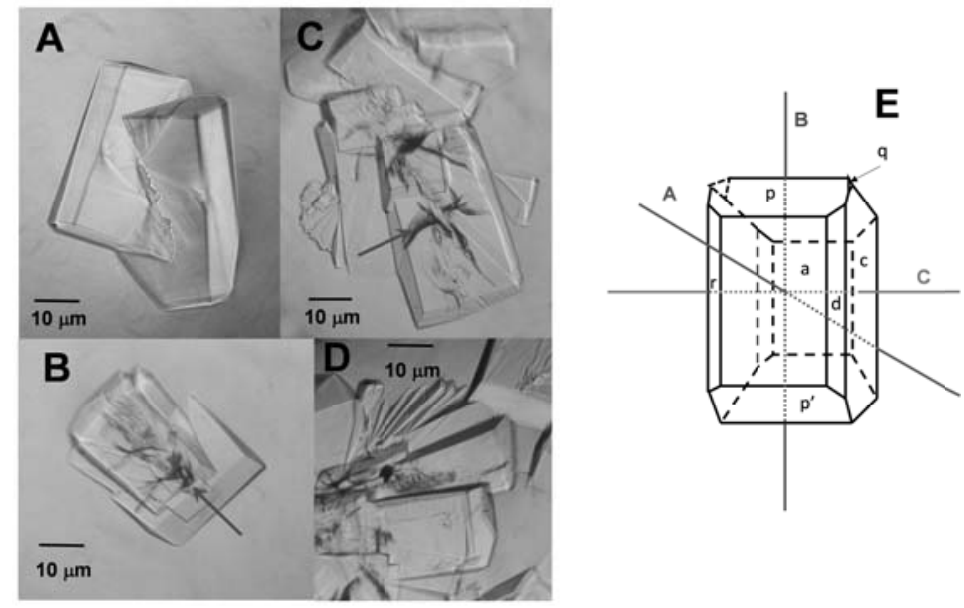

Figure 1. Different agglomerates of sucrose crystals after recrystallization from a $10 \%$ (w/v) solution of commercial sucrose in distilled water, showing agglomerates of two (A and B) or more (C and D), crystals. The crystallographic axes are shown in the diagram E. The red arrows indicate the presence of dislocation lines transformed into breakages.
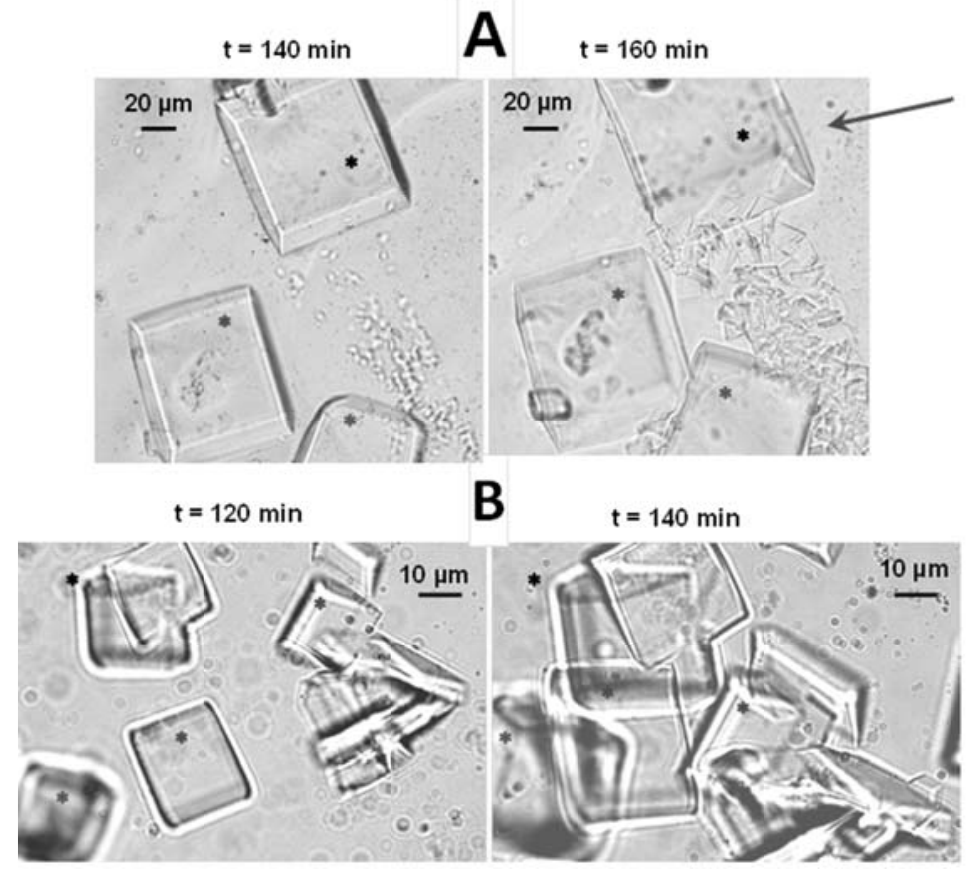

Figure 2. A) Growth of formed crystals of sucrose, labelled with an asterisk and appearance a new crystals growing from very small primers (red arrow) as a function of the time of recrystallization. B) Growth of formed crystals of sucrose, labelled with an asterisk, in the presence of sugar cane glycoproteins. 


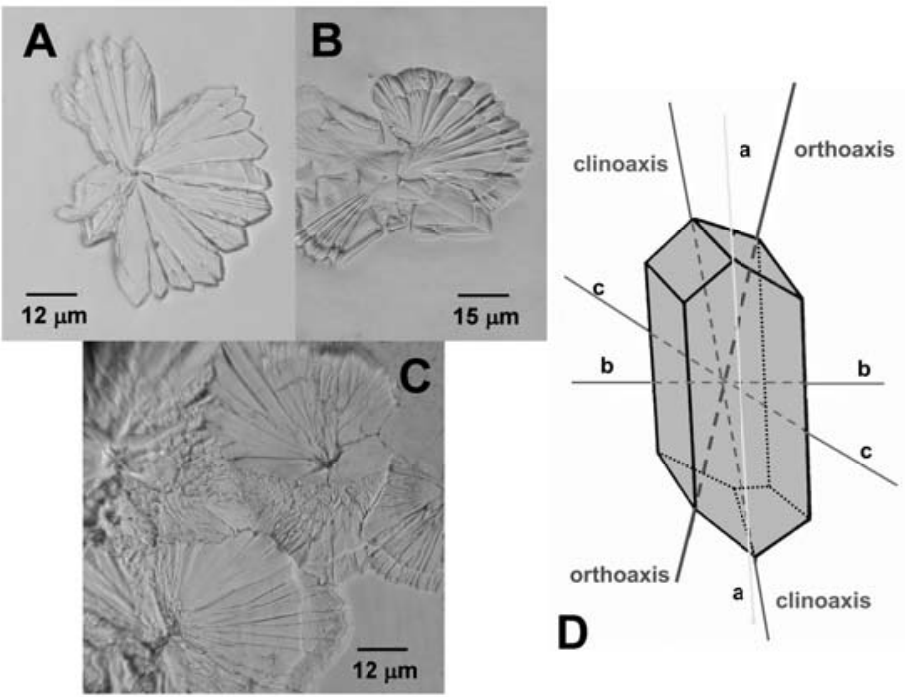

Figure 3. Different star-like agglomerates of sucrose crystals after recrystallization from a $10 \%(\mathrm{w} / \mathrm{v})$ solution of commercial sucrose in distilled water (A-C). In D, symmetry axes of an ideal crystal of monoclinic sphenoidal system are shown.

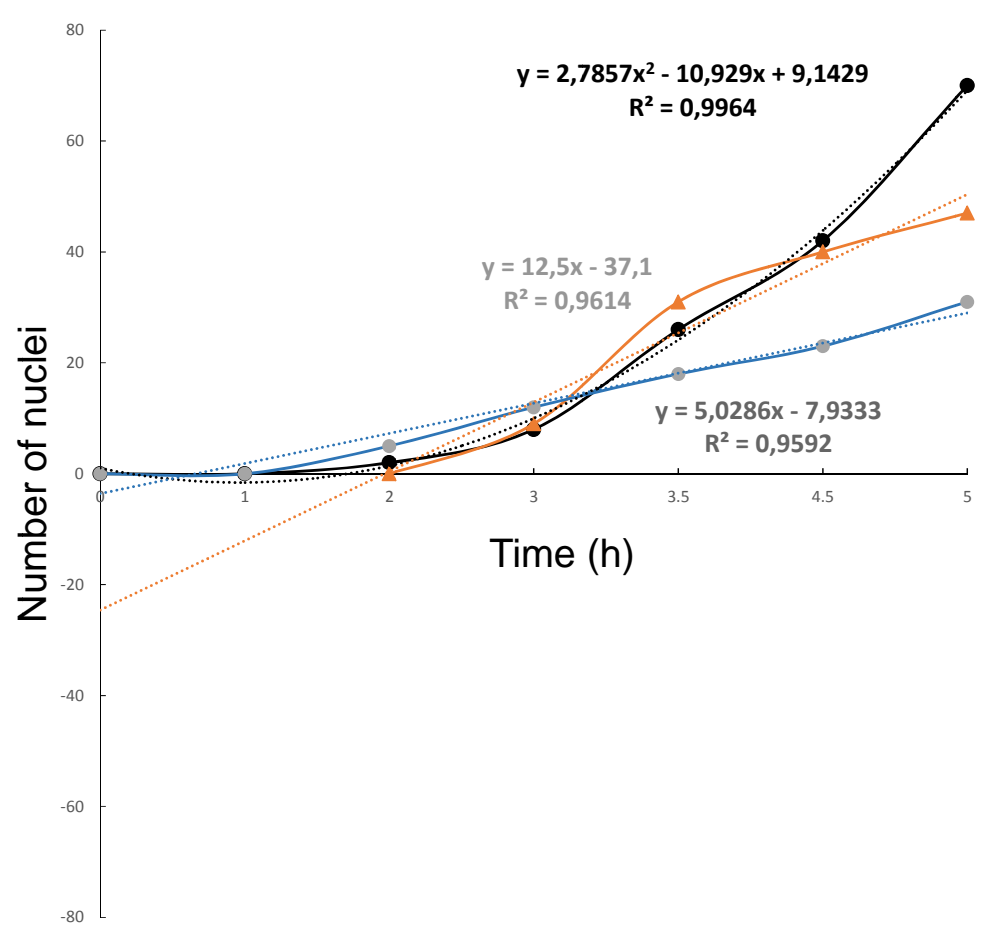

Figure 4. Recrystallization rate of sucrose in saturated aqueous solutions in absence

of any impurity, in the presence of HMMG sugarcane glycoproteins $(\mathbf{A})$ or xanthans purified from Xanthomonas alibilineans 


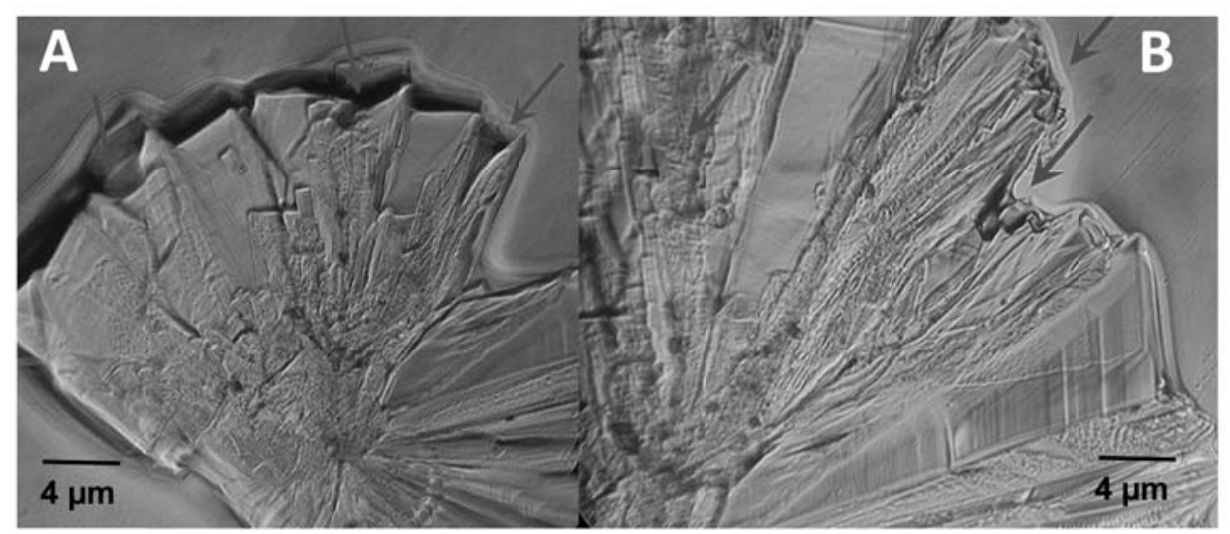

Figure 5. Star-like agglomerates of sugar crystals (A and B) formed in the presence of a xanthan produced by Xanthomonas albilineans at $24 \mathrm{~h}$ recrystallization. Arrows indicate the abrasion zones.

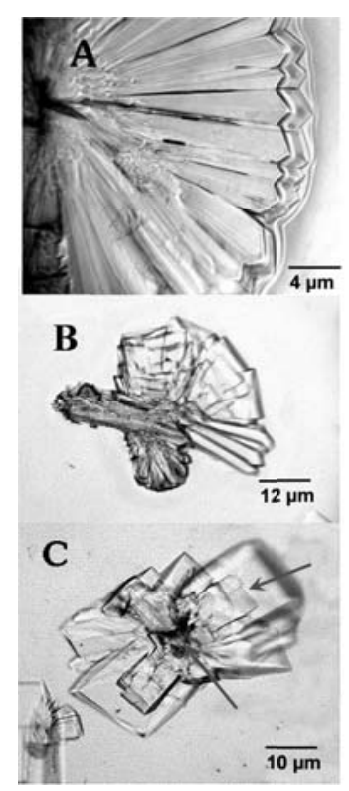

Figure 6. Recrystallization of sucrose from saturated aqueous solutions in distilled water (A), $0.5 \mathrm{mg} \mathrm{mL}-1 \mathrm{high}$ molecular mass (B) and $0.5 \mathrm{mg}$ mL-1 mid-molecular mass (C) glycoproteins obtained from sugar cane plants inoculated with teliospores of smut. 


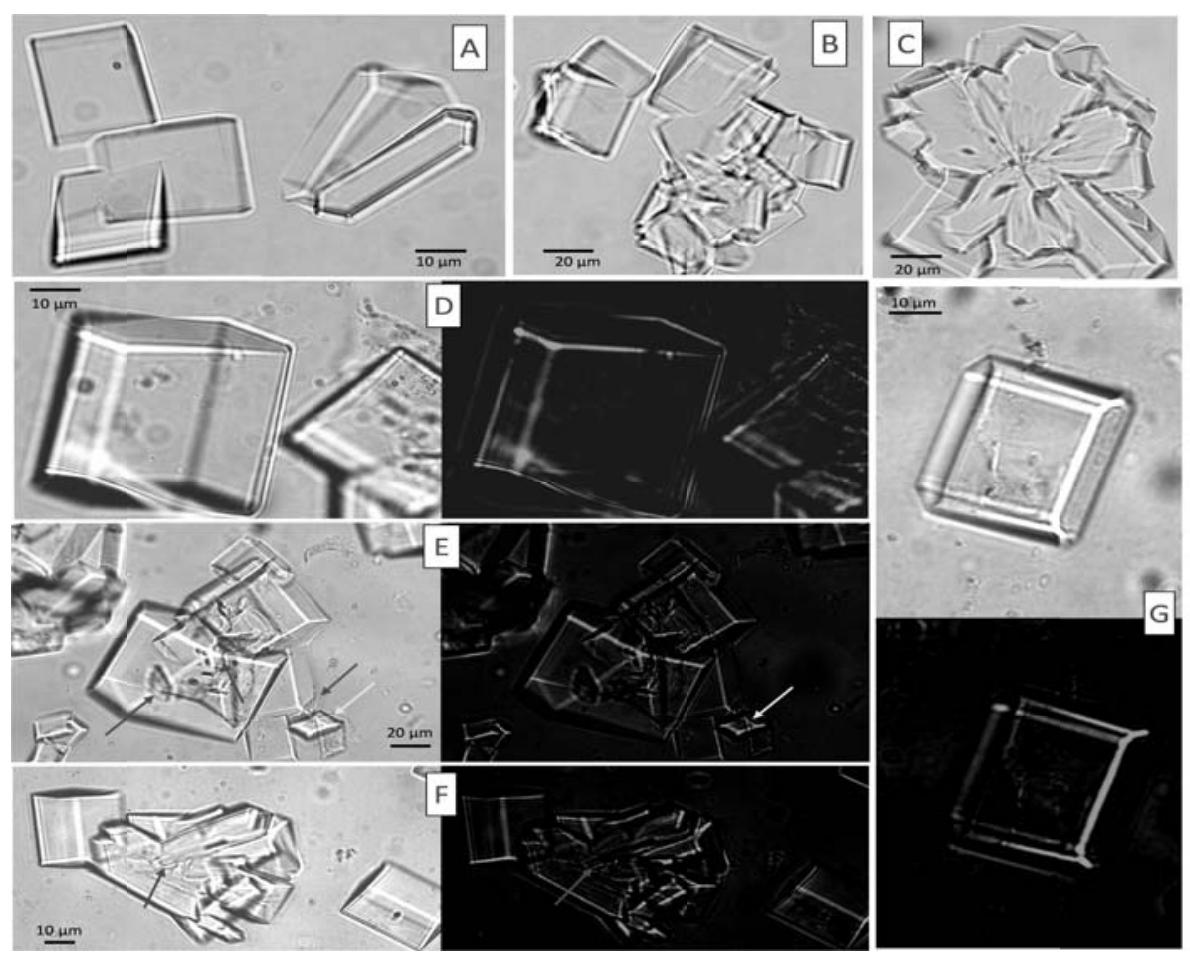

Figure 7. Recrystallization from $20 \%$ (w/v) sucrose aqueous solutions in distilled water (A-C) or in an aqueous solution containing 0.625 mg-mL-1 FITC-labelled HMMG, obtained from sugar cane plants inoculated with teliospores of smut (D-G) and labelled as described in [28], observed in light field or by fluorescence microscopy. Red arrows, crystal break lines; yellow arrow, ring of fluorescent glycoprotein shifting superficially along the main axis of the crystal (B axis in Fig. 1) 